СТАТЬЯ

УДК 631.4

ИЗМЕНЕНИЕ ПОЧВЕННЫХ СВОЙСТВ В ОРОШАЕМОМ ЗЕМЛЕДЕЛИИ

Кузиев Р.К., Собитов У.Т., Абдурахмонов Н.Ю., Мирсодиков М.М.

Научно-исследовательский институт почвоведения и агрохимии, Ташкент, e-mail: ulmasbek.sobitov@gmail.com

В статье подробно изложены новые данные о современном состоянии и таких свойствах почв, как механический состав, содержание гумуса и питательных элементов, а также степени засоления староорошаемых сероземно-луговых и луговых почв Мирзачуля, определенных в результате комплексных исследований. Отмечены изменения, протекающие в них в результате орошаемого земледелия. Преобладание физической глины в механическом составе гидроморфных почв относительно полугидроморфных, еще раз доказывает накопление илистых частиц в почвенном профиле в результате длительного орошения. На староорошаемых луговых почвах мощность гумусного горизонта равна мощности агроирригационного горизонта, и на основе полевых исследований отмечено, что мощность новоорошаемых луговых почв меньше, а на новоосвоенных почвах она равна пахотному горизонту. Отмечено, что агроирригационный горизонт староорошаемых почв Мирзачульского оазиса темно-бурый, зернистый, среднеуплотненный, в некоторых случаях наблюдается обильное накопление корней. Кроме того, в статье отмечено, что общефизические, водно-физические, физико-химические, агрохимические, биологические и другие свойства староорошаемых луговых почв тесно связаны с ее механическим составом. Также с механическим составом связаны тепловой режим почвы, ее температурный режим, физико-механические свойства почвы, их агрономическая оценка, технологии обработки, миграция, накопление солей и процессы вторичного засоления.

Ключевые слова: Голодная степь, оазис, сероземно-луговые и луговые почвы, механический состав, гумус, питательные элементы, засоление, гипс, карбонаты, грунтовые воды, эволюция, агроирригационный горизонт, гидроморфизм, плодородие

\title{
CHANGE OF SOIL PROPERTIES IN IRRIGATED AGRICULTURE
}

Kuziev R.K., Sobitov U.T., Abdurakhmonov N.Yu., Mirsodikov M.M.

Research Institute of Soil Science and Agrochemistry, Tashkent, e-mail: ulmasbek.sobitov@gmail.com

\begin{abstract}
The article presents in detail new data on the current state and soil properties such as the mechanical composition, humus and nutrient content, as well as the degree of salinization of the old irrigated serozem-meadow and meadow soils of Mirzachul, determined as a result of complex studies. The changes occurring in them as a result of irrigated agriculture are noted. The prevalence of physical clay in the mechanical composition of hydromorphic soils is relatively semi-hydromorphic, once again proves the accumulation of silty particles in the soil profile as a result of prolonged irrigation. On old irrigated meadow soils, the thickness of the humus horizon is equal to the thickness of the agro-irrigation horizon, and based on field studies, it was noted that the thickness of newly irrigated meadow soils is less, and on newly developed soils, it is equal to the arable horizon. It was noted that the agro-irrigation horizon of the old irrigated soils of the Mirzachul oasis is dark brown, granular, medium-compacted, in some cases abundant root accumulation is observed. In addition, the article notes that the general physical, water-physical, physico-chemical, agrochemical, biological and other properties of old irrigated meadow soils are closely related to its mechanical composition. The thermal composition of the soil, its temperature regime, physical-mechanical properties of the soil, their agronomical assessment, processing technologies, migration, salt accumulation and secondary salinization processes are also associated with the mechanical composition.
\end{abstract}

Keywords: Hungry steppe, oasis, serozem-meadow and meadow soils, mechanical composition, humus, salinity, groundwater, evolution, agro-irrigation horizon, fertility

Роль почвы в жизни человека чрезвычайно важна и незаменима. Почва является биокосным элементом, и она формируется в результате взаимодействия почвообразующих факторов в определенном естественногеографическом пространстве. Её возникновение, распространение и формирование плодородия не случайный процесс, а происходит по природным закономерностям. Изучение данных закономерностей, оптимизация почвенных свойств, определение факторов, лимитирующих плодородие почв, и, в частности, организация рационального и эффективного использования почвенных ресурсов имеют большое значение.
Количество поливной воды в современном орошаемом земледелии, которое влияет на процесс почвообразования и меняет основные свойства почв, в несколько раз превышает количество естественных осадков. В результате происходит поднятие уровня грунтовых вод в районах с затрудненным естественным стоком. По имеющимся данным, в настоящее время на большинстве орошаемых площадей уровень грунтовых вод достигает 2-3 м и оказывает влияние на развитие почв. Что стало причиной перехода почв из автоморфного режима в полугидроморфные и гидроморфные условия и привело к поднятию солей минерализо- 
ванных грунтовых вод до верхних почвенных горизонтов.

Цель исследования: изучение изменений в свойствах орошаемых сероземно-луговых и луговых почв, протекающих под влиянием орошаемого земледелия, на основе комплексных исследований почв Мирзачульского оазиса.

\section{Материалы и методы исследования}

Объектом исследования служили сероземно-луговые и луговые почвы, типичные для области по природным и антропогеннохозяйственным условиям, культуре земледелия, уровню землепользования, почвенным свойствам и современному состоянию их плодородия, урожайности культур, распространенные на различных геоморфологических районах Мирзачульского оазиса.

Основу методов исследований составили сравнительно-географический анализ данных изученных регионов, лабораторноаналитические работы выполнены на основе общепринятых методов $[1,2]$.

\section{Результаты исследования и их обсуждение}

Средняя высота Мирзачульской равнины составляет 250-310 м над уровнем моря, а самая высокая ее часть приходится на юго-восток, к головной части оросительных каналов, с высотой 350 м. Самая низкая часть впадин и солончаков данного направления расположена в 230 м над уровнем моря. Мирзачульская равнина снижается на север и северо-запад.

Относительная влажность воздуха сравнительно низкая, самая низкая относительная влажность наблюдается в июне-августе, со среднегодовой влажностью воздуха около 31-48\%. Повышение температуры воздуха в летние месяцы приводит к более интенсивному испарению влаги, что значительно выше среднегодового количества осадков. Данный климат приводит к засолению почв и увеличению потребности сельскохозяйственных культур в воде [3].

Орошаемые сероземно-луговые почвы по своему происхождению образуют ряд промежуточных «переходных» почв. Эти почвы с умеренным влиянием грунтовых вод (2-3 м) наиболее широко распространены в Сырдарьинской области. Они сформированы в результате нарушения баланса и повторного поднятия уровня грунтовых вод на Центральной Мирзачульской равнине пояса светлых сероземов. За счет постоянного поднятия уровня подземных вод, сероземно-луговые почвы капиллярно увлажняются до верхних слоев, а на нижних горизонтах образуются тускло-зеленые пятна с серым оттенком. Подземные воды залегают на глубине 2-3 м и периодически поднимаются до верхних слоев. Эти почвы подвержены быстрому засолению, в различной степени засолены, тип засоления хлоридно-сульфатный и сульфатно-хлоридный, слабо, иногда средне гипсированы. На орошаемых сероземно-луговых почвах южных предгорных массивов наблюдается процесс слабой ирригационной эрозии, юго-восточные территории подвержены ветровой эрозии. Здесь продолжается эволюционное развитие от сероземно-луговых к луговым почвам [4].

Oрошаемые луговые почвы сформированы в условиях с уровнем залегания подземных вод на глубине 1-2 м. Они широко распространены на II-I террасах Сырдарьи, на низменностях и впадинах, делювиально-пролювиальных, лессовидных и озерно-аллювиальных отложениях Центрального Мирзачула, в основном встречаются в районах с сероземно-луговыми и луговосероземными почвами. Эти почвы сформированы в условиях постоянной влажности почвенного профиля, в результате чего автоморфные сероземы, постоянно меняясь, перешли в промежуточные сероземно-луговые и в итоге в гидроморфные луговые почвы. Со временем сформировались внешние морфологические признаки луговых почв и образовалась флора, типичная для данного типа почв. Кроме того, в условиях переувлажнения постоянного гидроморфизма возникли анаэробные условия и образовались оксиды и соединения железа, алюминия, марганца. Нижние участки почвы имеют коричневато-серый тусклый оттенок, близкое залегание подземных вод привело к вторичному засолению. Поэтому для эффективного использования луговых почв необходимо обеспечить должную работу коллекторно-дренажной системы [4].

Пахотный горизонт изученных орошаемых луговых почв имеет светло-бурый цвет, на лугово-аллювиальных почвах бурый, слабо уплотненный, обильно встречаются остатки растительности. Подпахотный горизонт средне и сильно уплотненный и имеет комковатую структуру. Встречаются корни и корешки, иногда солевые пятна.

В верхнем (60-70 см) слое староосвоенных и орошаемых луговых почв вблизи Сырдарьи сформирован агроирригационный слой, они имеют одинаковый цвет и механический состав, нижние слои состоят из слоев с различным механическим составом. Также можно наблюдать накопление большого количества признаков гидроморфизма в нижних слоях - коричневых и бледных пятен, кристаллов солей и гипса. 
На староорошаемых луговых почвах мощность гумусового горизонта равна толщине агроирригационного слоя, тогда как на новоорошаемых луговых почвах мощность гумусового горизонта меньше (40-50 см), а на новоосвоенных ограничивается пахотным слоем. В агроирригационном слое почв Мирзачулья темно-коричневые, зернистые, умеренно уплотненные упакованные, в некоторых случаях наблюдается обильное накопление корней растительности.

Общефизические, водно-физические, физико-химические, агрохимические, биологические и другие свойства почвы тесно связаны с ее механическим составом. Кроме того, тепловой режим почвы, ее температурный режим, такие физико-механические свойства, как удельное сопротивление при обработке, сроки зрелости почвы и другие свойства почвы, их агрономическая оценка, технологии обработки почвы, миграция солевых растворов в почвенных горизонтах, накопление солей и виды процессов вторичного засоления, водно-солевые режимы и баланс, влажности почвы и содержание питательных веществ, необходимых для растений, также связаны с механическим составом почв $[5,6]$.

Механический состав староорошаемых сероземно-луговых почв в основном среднесуглинистый, в некоторых случаях в нижних горизонтах сменяется легкими суглинками. Количество физической глины (размер частиц менее $<0,01$ мм) составляет 20,0-44,4\%, характерно преобладание крупных частиц пыли (0,05-0,01 мм), в почвенных горизонтах они составляют $36,4-51,3 \%$, частицы средней пыли $(0,01-$ 0,005 мм) составляют 2,3-22,0\%, частицы мелкой пыли (0,005-0,001 мм) - 2,8-17,9\%, частицы мелкого песка $(0,1-0,05$ мм) составляют 4,8-21,9\%, а количество илистых частиц составляет 8,2-16,6\% (табл. 1).

Орошаемые луговые почвы распространены во всех геоморфологических районах Сырдарьинской области. Согласно механическому составу, в староосвоенных северо-восточных районах региона распространены средние и тяжелые суглинки, а в новоосвоенных юго-западных и западных частях региона преобладают легкосуглинистые почвы.

Механический состав староорошаемых луговых почв исследуемой территории в основном тяжелосуглинистый, а нижние слои - средне и легкосуглинистые, количество частиц физической глины (менее $<0,01$ мм) колеблется в пределах $45,6-80,7 \%$, количество частиц крупной пыли (0,05-0,01 мм) в почвенном профиле составляет $18,1-48,4 \%$, а частицы средней пыли (0,01-0,0000 мм) варьируют в широких пределах и составляют 11,3-33,4\%, частицы мелкой пыли (0,005-0,001 мм) наблюдаются в диапазоне 17,3-36,6\%, содержание илистых частиц составляет $13,2-$ $17,4 \%$, а в нижних слоях - 20,0-22,5\%.

Утяжеление механического состава луговых почв по сравнению с сероземно-луговыми почвами обусловлено накоплением илистых частиц в почвенном профиле в результате длительного орошения.

Орошение оказывает большое влияние на содержание и запасы гумуса и питательных веществ в почве. Этот процесс, с одной стороны, связан с системным удобрением почв гумусом и выращиванием культурных растений, которые оставляют в почве большое количество корневых остатков, что может привести к накоплению органических веществ в почве. Но, с другой стороны, обработка почвы и орошение ускоряют биологические процессы, особенно разложение органических веществ. В первые годы освоения территории сероземного пояса Центрально-Азиатского региона орошение и возделывание в некоторых случаях стали причиной уменьшения гумуса и других органических веществ. Однако в результате последующих применений агромероприятий, с целью повышения плодородия орошаемых почв, начинают увеличиваться запасы гумуса. По мнению ряда исследователей, вспашки и орошение целинных сероземов ускоряют процессы разложения и минерализации органического вещества. В первые 3-4 года освоения целинных почв разлагаются 40-50\% всего органического вещества новоорошаемых сероземов, на вновь орошаемых песчаных почвах, впоследствии этот процесс стабилизируется [7].

Количество гумуса в почвах исследуемых территорий является основным фактором, управляющим рядом свойств почв, в зависимости от условий гумусообразования, механического состава профиля, периода орошения, культуры земледелия, мощности агроирригационного горизонта и степени засоления. Содержание гумуса в верхнем слое пахотного горизонта в количестве $0,80-1,02 \%$, в подпахотном горизонте - 0,56-1,04\%, а к нижним горизонтам наблюдается снижение его содержания до $0,27-0,48 \%$. По содержанию гумуса эти почвы относятся к низко (0,5-1\%) и средне (1-1,5\%) гумусированным группам, содержание общего азота составляет 0,052-0,071\%, а в нижних горизонтах его содержание колеблется в пределах 0,024-0,042\%. 


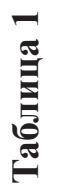
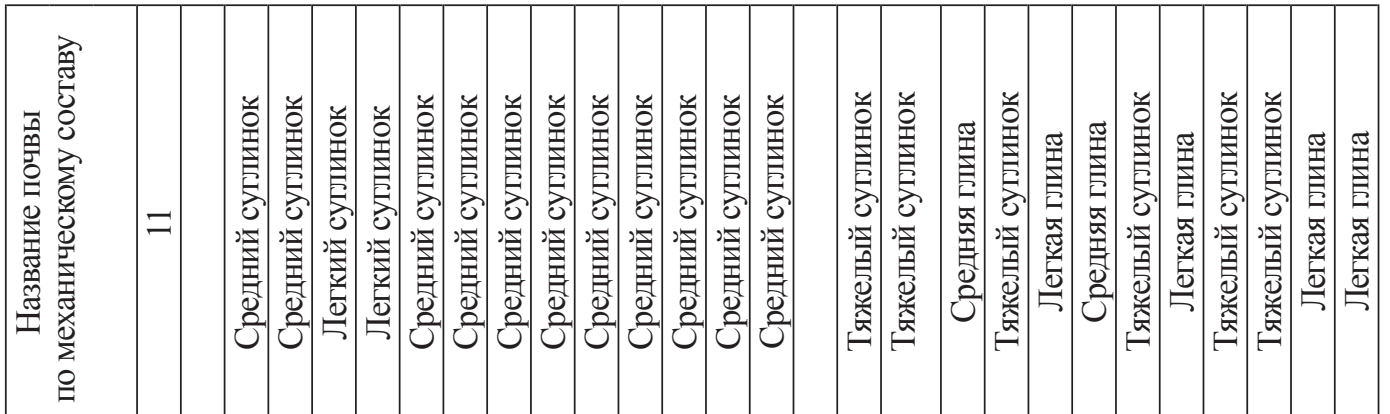

茞

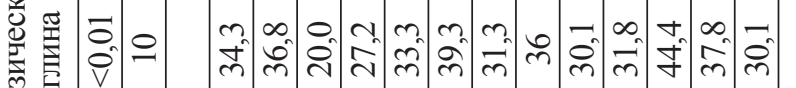

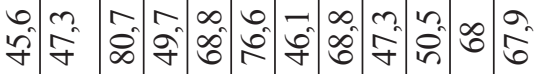
总

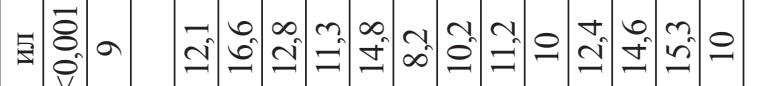

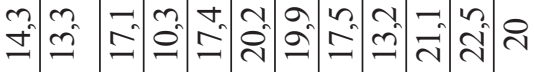

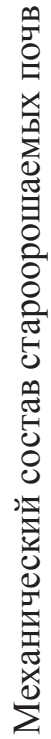

$\overline{8}$

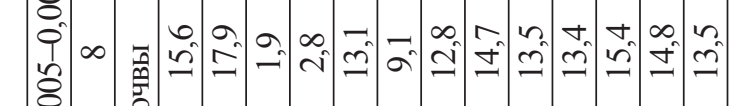

* 寄

壳

魚

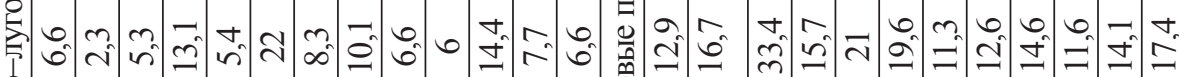

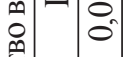

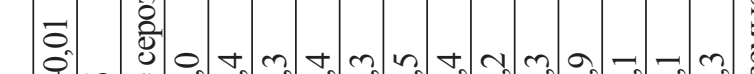

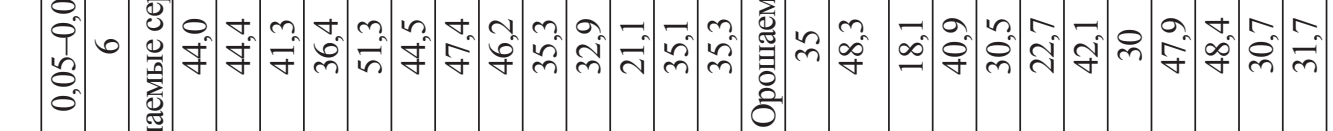

年

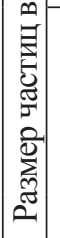

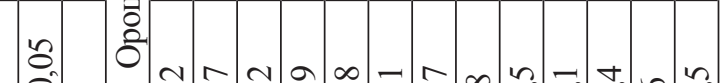

I.

है।

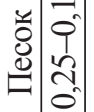

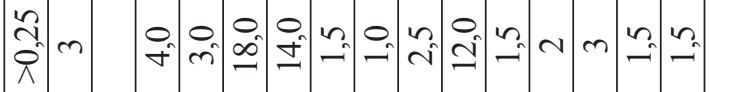

กิ-

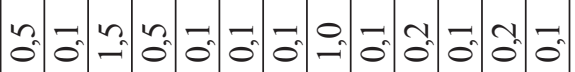

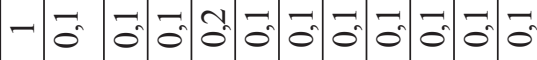

ซึึ:

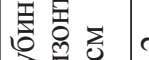

흘

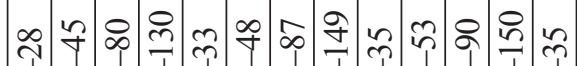

d

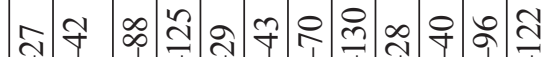

ग)

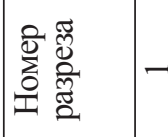


Таблица 2

Содержание гумуса и питательных элементов в староорошаемых почвах

\begin{tabular}{|c|c|c|c|c|c|c|c|c|}
\hline \multirow{3}{*}{$\begin{array}{l}\text { Номер } \\
\text { разреза }\end{array}$} & \multirow{3}{*}{$\begin{array}{c}\text { Глубина } \\
\text { горизонта, } \\
\text { см }\end{array}$} & \multirow{3}{*}{$\begin{array}{c}\text { Гумус, } \\
\% \%\end{array}$} & \multirow{3}{*}{$\begin{array}{c}\text { Общий } \\
\text { азот } \\
\%\end{array}$} & \multirow[t]{3}{*}{$\mathrm{C}: \mathrm{N}$} & \multicolumn{4}{|c|}{ Питательные элементы } \\
\hline & & & & & \multicolumn{2}{|c|}{ валовые, \% } & \multicolumn{2}{|c|}{ подвижные, мг/кг } \\
\hline & & & & & фосфор & калий & $\mathrm{P}_{2} \mathrm{O}_{5}$ & $\mathrm{~K}_{2} \mathrm{O}$ \\
\hline \multicolumn{9}{|c|}{ Орошаемые сероземно-луговые почвы } \\
\hline \multirow{4}{*}{1} & $0-28$ & 1,02 & 0,071 & 8,3 & 0,131 & 0,885 & 7,33 & 155 \\
\hline & $28-45$ & 1,04 & 0,075 & 8,0 & 0,137 & 0,845 & 4,67 & 130 \\
\hline & $45-80$ & 0,45 & 0,035 & 7,5 & 0,063 & 0,712 & 1,33 & 47 \\
\hline & $80-130$ & 0,48 & 0,042 & 6,6 & 0,080 & 0,733 & 2,0 & 15 \\
\hline \multirow{4}{*}{2} & $0-33$ & 0,90 & 0,052 & 10,0 & 0,125 & 0,852 & 14,93 & 131 \\
\hline & $33-48$ & 0,78 & 0,043 & 10,5 & 0,128 & 0,860 & 6,0 & 93 \\
\hline & $48-87$ & 0,36 & 0,029 & 7,2 & 0,115 & 0,639 & 3,33 & 15 \\
\hline & $87-149$ & 0,35 & 0,031 & 6,5 & 0,082 & 0,758 & 2,67 & 15 \\
\hline \multirow{4}{*}{3} & $0-35$ & 0,80 & 0,058 & 8,0 & 0,145 & 0,850 & 18,93 & 130 \\
\hline & $35-53$ & 0,56 & 0,044 & 7,4 & 0,140 & 0,700 & 9,43 & 131 \\
\hline & $53-90$ & 0,33 & 0,029 & 6,6 & 0,142 & 0,550 & 3,33 & 123 \\
\hline & $90-150$ & 0,27 & 0,024 & 6,5 & 0,125 & 0,420 & 2,00 & 118 \\
\hline \multicolumn{9}{|c|}{ Орошаемые луговые почвы } \\
\hline \multirow{4}{*}{4} & $0-27$ & 1,05 & 0,070 & 8,70 & 0,185 & 1,04 & 42,0 & 108 \\
\hline & $27-42$ & 0,98 & 0,065 & 8,74 & 0145 & 0,89 & 17,6 & 95 \\
\hline & $42-88$ & 0,68 & 0,050 & 7,89 & 0,155 & 0,78 & 8,2 & 55 \\
\hline & $88-125$ & 0,50 & 0,044 & 6,89 & 0,106 & 0,99 & 7,9 & 48 \\
\hline \multirow{4}{*}{5} & $0-29$ & 1,26 & 0,090 & 8,12 & 0,165 & 1,00 & 18,6 & 130 \\
\hline & $29-43$ & 0,91 & 0,750 & 7,04 & 0,182 & 0,89 & 10,8 & 118 \\
\hline & $43-70$ & 0,89 & 0,079 & 6,53 & 0,123 & 0,82 & 12,6 & 115 \\
\hline & $70-130$ & 0,83 & 0,074 & 6,51 & 0,136 & 0,70 & 8,0 & 100 \\
\hline \multirow{4}{*}{6} & & 1,76 & & & 0,172 & 0,85 & 11,47 & \\
\hline & $28-40$ & 1,43 & 0,105 & 7,90 & 0,146 & 0,55 & 9,47 & 118 \\
\hline & $40-96$ & 1,08 & 0,086 & 7,28 & 0,150 & 0,68 & 8,0 & 88 \\
\hline & $96-122$ & 0,60 & 0,053 & 6,57 & 0,128 & 0,49 & 8,0 & 95 \\
\hline
\end{tabular}

Содержание общих форм фосфора в пахотном и подпахотном горизонтах почв составляет $0,125-0,145 \%$, а количество подвижного фосфора равно 4,6718,93 мг/кг, и отмечено снижение его содержания вниз по профилю. Содержание общего калия в верхних слоях почв составляет $0,850-0,855 \%$, а количество обменного калия в пахотном горизонте составляет 131-155 мг/кг, и наблюдается уменьшение его количества в нижних горизонтах. Исследованные почвы по уровню обеспеченности подвижным фосфором относятся к очень низкообеспеченным, а по содержанию обменного калия - к низкообеспеченным группам (табл. 2).

Отмечено, что содержание гумуса в пахотном горизонте луговых почв составляет $1,05-1,76 \%$, в подпахотном горизонте $0,91-1,43 \%$ и уменьшается до $0,50-1,08 \%$ в нижних слоях почвенного профиля. Содержание общего азота в пахотном горизонте составляет $0,070-0,122 \%$, а в подпахотном и нижних горизонтах его содержание равно $0,044-0,105 \%$.
Общее содержание фосфора в пахотном и подпахотном горизонтах почв составляет $0,155-0,182 \%$, а количество подвижного фосфора составляет 9,47-42,0 мг/кг, и его содержание снижается вниз по профилю. В верхних слоях почвенного покрова общее содержание калия составляет 0,550-1,040\%, а количество обменного калия в пахотном горизонте исследованных почв составляет 95-131 мг/кг, и наблюдается уменьшение его содержания в нижних слоях почв. По уровню обеспеченности подвижным фосфором почвы относятся к очень низко и средне обеспеченным группам, а по содержанию калия - к очень низко и низко обеспеченным группам (табл. 2). Установлено, что на староорошаемых луговых почвах эти показатели выше, по сравнению с сероземно-луговыми.

До освоения Мирзачульской степи почвы преимущественно были незасоленными и слабозасоленными и характеризовались глубиной залегания грунтовых вод на уровне 15-20 м. Освоение этих территорий велось без дренажных сооружений. 
Таблица 3

Состав водной вытяжки, содержание гипса и $\mathrm{CO}_{2}$ карбонатов староорошаемых почв (в \% относительно абс. сухой почве)

\begin{tabular}{|c|c|c|c|c|c|c|c|c|c|c|}
\hline $\begin{array}{l}\text { Номер } \\
\text { разреза }\end{array}$ & $\begin{array}{c}\text { Мощность } \\
\text { горизонта, } \\
\text { см }\end{array}$ & $\begin{array}{c}\text { Сухой } \\
\text { остаток }\end{array}$ & $\mathrm{HCO}_{3}^{-}$ & $\mathrm{CI}^{-}$ & $\mathrm{SO}_{4}^{2-}$ & $\mathrm{Ca}^{2+}$ & $\mathrm{Mg}^{2+}$ & $\mathrm{Na}^{+}$ & $\begin{array}{c}\mathrm{CO}_{2} \\
\text { карбонаты }\end{array}$ & $\begin{array}{c}\mathrm{SO}_{4} \\
\text { гипс }\end{array}$ \\
\hline 1 & 2 & 3 & 4 & 5 & 6 & 7 & 8 & 9 & 10 & 11 \\
\hline \multicolumn{11}{|c|}{ Орошаемые сероземно-луговые почвы } \\
\hline \multirow[t]{4}{*}{1} & $0-28$ & 0,174 & 0,025 & 0,007 & 0,044 & 0,018 & 0,004 & 0,007 & 8,8 & 0,518 \\
\hline & $28-45$ & 0,190 & 0,023 & 0,004 & 0,057 & 0,024 & 0,005 & 0,001 & 9,2 & 0,317 \\
\hline & $45-80$ & 0,966 & 0,013 & 0,007 & 0,515 & 0,186 & 0,019 & 0,006 & 10,1 & 0,689 \\
\hline & $80-130$ & 0,872 & 0,014 & 0,008 & 0,475 & 0,168 & 0,019 & 0,009 & 8,7 & 0,765 \\
\hline \multirow[t]{4}{*}{2} & $0-33$ & 0,124 & 0,025 & 0,013 & 0,038 & 0,016 & 0,004 & 0,01 & 8,2 & 0,662 \\
\hline & $33-48$ & 0,186 & 0,023 & 0,020 & 0,052 & 0,018 & 0,006 & 0,014 & 8,9 & 0,518 \\
\hline & $48-87$ & 0,372 & 0,019 & 0,029 & 0,166 & 0,042 & 0,016 & 0,027 & 9,5 & 0,346 \\
\hline & $87-149$ & 0,714 & 0,014 & 0,014 & 0,385 & 0,110 & 0,024 & 0,027 & 10,3 & 0,490 \\
\hline \multirow[t]{4}{*}{3} & $0-35$ & 0,461 & 0,021 & 0,039 & 0,202 & 0,036 & 0,035 & 5,633 & 8,12 & 0,195 \\
\hline & $35-53$ & 0,440 & 0,027 & 0,035 & 0,218 & 0,036 & 0,045 & 5,978 & 8,14 & 0,260 \\
\hline & $53-90$ & 0,816 & 0,024 & 0,035 & 0,473 & 0,080 & 0,049 & 11,24 & 10,15 & 0,332 \\
\hline & $90-150$ & 1,019 & 0,027 & 0,067 & 0,576 & 0,106 & 0,084 & 14,32 & 9,01 & 3,665 \\
\hline \multicolumn{11}{|c|}{ Орошаемые луговые почвы } \\
\hline \multirow[t]{4}{*}{4} & $0-27$ & 0,484 & 0,017 & 0,027 & 0,239 & 0,056 & 0,017 & 6,01 & 6,38 & 0,58 \\
\hline & $27-42$ & 0,122 & 0.025 & 0,008 & 0.042 & 0,012 & 0,002 & 1,50 & 9,72 & 0,62 \\
\hline & $42-88$ & 0,242 & 0,024 & 0,014 & 0,126 & 0,022 & 0,007 & 3,40 & 9,89 & 4,21 \\
\hline & $88-125$ & 0,056 & 0,018 & 0,006 & 0,020 & 0,006 & 0,001 & 0,88 & 10,53 & 1,07 \\
\hline \multirow[t]{4}{*}{5} & $0-29$ & 0,348 & 0,031 & 0,052 & 0,106 & 0,052 & 0,005 & 4,190 & 9,64 & 0,16 \\
\hline & $29-43$ & 0,148 & 0,021 & 0,024 & 0,042 & 0,007 & 0,006 & 1,914 & 10,10 & 0,21 \\
\hline & $43-70$ & 0,168 & 0,027 & 0,017 & 0,029 & 0,068 & 0,007 & 1,543 & 10,10 & 3,76 \\
\hline & $70-130$ & 0,256 & 0,031 & 0,024 & 0,082 & 0,009 & 0,007 & 2,904 & 9,64 & 1,11 \\
\hline \multirow[t]{4}{*}{6} & $0-28$ & 0,260 & 0,027 & 0,042 & 0,082 & 0,009 & 0,007 & 3,57 & 7,96 & 0,16 \\
\hline & $28-40$ & 0,166 & 0,027 & 0,014 & 0,062 & 0,006 & 0,007 & 2,124 & 8,68 & 0,21 \\
\hline & $40-96$ & 0,204 & 0,024 & 0,025 & 0,070 & 0,007 & 0,005 & 2,821 & 9,62 & 0,76 \\
\hline & $96-90$ & 0,166 & 0,030 & 0,017 & 0,063 & 0,006 & 0,006 & 2,313 & 10,85 & 1,02 \\
\hline
\end{tabular}

В результате под влиянием орошения поднялся «критический» уровень грунтовых вод. В процессе формирования почвы начали переходить в гидроморфную форму и активировалась миграция первичных солей, что в результате привело к различной степени засоления почв.

Согласно анализу водной вытяжки староорошаемых сероземно-луговых почв, содержание сухого остатка в пахотном горизонте составляет $\quad 0,174-0,461 \%, \quad$ в подпахотном горизонте - 0,186-0,440\% и 0,372-1,019\% в нижних слоях почвенного профиля (табл. 3).

В этих почвах тип засоления в основном хлоридно-сульфатный и сульфатный, по степени засоления верхние слои $(0-50$ см) почв незасоленные, слабозасоленные.

Общее количество солей в пахотном горизонте луговых почв, по сухому остатку, составляет 0,260-0,484\%, а на подпахотном и нижних горизонтах - 0,056-0,256\%, тип засоления в основном хлоридно-сульфатный и сульфатный, по степени засоления данные почвы в большинстве случаев относятся к незасоленным, слабозасоленным, а в некоторых случаях к среднезасоленным группам. Содержание гипса в этих почвах не превышает $0,8-1,0 \%$, но в отдельных горизонтах почвенного профиля достигает 3-4\% (табл. 3). Содержание $\mathrm{SO}_{2}$ карбонатов в профиле сероземно-луговых и луговых почв распространено практически равномерно и колеблется в пределах от 7 до 9\%, а в нижних слоях его содержание достигает $10-12 \%$.

\section{Заключение}

Механический состав изученных почв, в зависимости от характера материнской породы, состоит в основном из средних, легких и тяжелых суглинков. Во всех случаях превалируют частицы крупной пыли (0,05-0,01 мм).

1. Количество гумуса в пахотном слое колеблется в пределах $0,80-1,76 \%$, по содержанию подвижного фосфора в профиле почвы относятся к очень низко и низко обеспеченным, а по содержанию обменного калия - к низко и средне обеспеченным группам. 
2. Небольшое увеличение количества $\mathrm{CO}_{2}$ карбонатов в нижних горизонтах почвенного профиля свидетельствует о вымывании и накоплении карбонатов в нижних горизонтах в результате длительного орошения.

\section{Список литературы}

1. Инструкция проведения почвенных исследований и составления почвенных карт для ведения Государственного земельного кадастра. Нормативные документы по землепользованию, землеустройству и земельному кадастру. Ташкент, 2009. 51 с.

2. Аринушкина Е.В. Руководство по химическому анализу почв. М.: МГУ, 1962. 491 с.

3. Ахмедов А.У., Баиров А.Ж., Парпиев Г.Т. Опыт почвенно-экологического и мелиоративного мониторинга на ключевых участках Голодной степи // Аграрная наука сельскому хозяйству: сборник статей Международной на- учно-практической конференции. Барнаул: Изд. АГАУ, 2016. Кн. 1. С. 59-62.

4. Собитов У.Т., Абдурахмонов Н.Ю. Характеристика и степень плодородия орошаемых почв Мирзачульского оазиса // Научное обозрение. Биологические науки. 2018. № 1. C. $23-27$.

5. Курвонтоев Р., Абдуллаев С., Аликулов Б. Водные свойства орошаемых сероземно-луговых почв Голодностепского оазиса // Аграрная наука - сельскому хозяйству: сборник статей Международной научно-практической конференции. Барнаул: Изд. АГАУ, 2016. Кн. 1. С. 126-128.

6. Курвантоев Р., Абдуллаев С., Турсунов Л., Абдушкурова 3. Современное состояние плодородия орошаемых почв Республики Узбекистан и проблема их повышения // Аграрная наука сельскому хозяйству: II Международная научно-практическая конференция. Барнаул, 2017. С. 54-56.

7. Ташкузиев М.М., Шадиева Н.И. Закономерности распространения гумуса и процессы гумусообразования в условиях почв предгорий Северного Туркестана // Вестник Каракалпакского отделения Академии Наук Республики Узбекистан. 2010. № 3 (216). С. 25-28. 